\title{
A comparative study on echocardiographic evaluation of the left ventricular mass and function in normotensive diabetic and non-diabetic patient
}

\author{
Tanmay Mukhopadhyay ${ }^{1}$, Pankaj Sarkar², Somnath Naskar ${ }^{3}$, Uttam Biswas ${ }^{4}$, \\ Saidul Islam SK ${ }^{5}$ \\ ${ }^{1}$ Assistant Professor, Department of Cardiology, ${ }^{4}$ Assistant Professor, Department of Medicine, Burdwan Medical \\ College and Hospital, Purba Burdhaman, ${ }^{2}$ Consultant Cardiologist, North City Hospital, ${ }^{3}$ Associate Professor, \\ Department of Community Medicine, ${ }^{5}$ Associate Professor, Department of Cardiology, IPGME\&R and SSKM Hospital, \\ Kolkata, West Bengal, India
}

A B S T R A C T

Background: Cardiovascular complications account for the highest mortality in diabetic patients, mainly due to coronary artery disease and congestive heart failure. Left ventricular hypertrophy (LVH) is an ominous prognostic sign and an independent risk factor for cardiac events which is frequently present in patients living with diabetes. Aims and Objectives: The aim of the study was to evaluate the LV mass and function in normotensive diabetes patients without antihypertensive medication. Materials and Methods: 100 normotensive diabetic patients were in study group and 100 control patients were studied. Hypertension and other known causes of LVH were excluded from the study. Data were analyzed using proper statistical method. Results: Left ventricular mass index (LVMI) is significantly higher in diabetic patients as compared to control population $(\mathrm{P}<0.001)$. It was also observed that the means of the left ventricular posterior wall thickness, interventricular septal thickness, and the left ventricular internal diameter during diastole (in all cases $\mathrm{P}<0.001$ ) were statistically significantly high in diabetic patients in comparison to healthy control subjects. We have found that a significant systolic dysfunction in diabetic group and diastolic dysfunction also very common in diabetic group than the control group. The LVMI also increased in patients who have longer duration of diabetes and poor glycemic control. Conclusion: LVM is significantly higher in patients of type 2 diabetic without having hypertension, albuminuria, and apparent ischemic heart disease as compared to healthy controls. LVM in diabetic patients increases with duration of diabetes and is positively correlated with $\mathrm{HbA} 1 \mathrm{c}$ and blood sugar level.

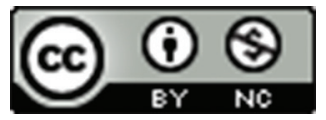

This work is licensed under a Creative Commons Attribution-NonCommercial 4.0 International License.

Key words: Diabetes mellitus; Left ventricular dysfunction; Left ventricular hypertrophy; Left ventricular mass index; Normotensive

\section{INTRODUCTION}

Cardiovascular disease is increased in individuals living with diabetes mellitus (DM) both type-1 and type-2. The Framingham Heart Study revealed a marked increase in peripheral arterial disease, congestive heart failure (CHF), coronary artery disease (CAD), myocardial infarction, and sudden death (risk increase from one- to five-fold) in DM. ${ }^{1}$ Cardiovascular complications account for the highest morbidity and mortality in patients with diabetes, mainly due to CAD and CHF. Diabetes is associated with a high prevalence of hypertension, dyslipidemia, obesity, and microalbuminuria. All are known independent cardiovascular risk factors. Even in populations with low cardiovascular risk, diabetes is associated with an increased incidence of cardiovascular death. ${ }^{2}$ 
Degree of increased myocardial muscle mass is a strong and independent risk factor for cardiac morbidity and mortality. ${ }^{3,4}$ In addition, the risk of ventricular arrhythmia is increased at least 2 times in the presence of the left ventricular hypertrophy $(\mathrm{LVH}) .{ }^{5}$ The significance of $\mathrm{LVH}$ is not widely appreciated in medicine. The Framingham Study showed that increased the left ventricular (LV) mass is associated with a significant excess of cardiovascular mortality and morbidity. ${ }^{1}$ This is independent of the presence of CAD or hypertension, with a tripling of the mortality rate in subjects with and without either of these. ${ }^{1}$

$\mathrm{LVH}$, which is an ominous prognostic sign and an independent risk factor for cardiac events, is often present in type $2 \mathrm{DM}$ patients. ${ }^{6}$ The possible contributions of hyperinsulinemia and hyperglycemia to the left ventricular mass (LVM) have been suggested in the normotensive and hypertensive subjects without diabetes. ${ }^{6}$ Hyperinsulinemia, which is possibly associated with insulin resistance, may promote concentric changes in LV geometry in normotensive and mildly to moderately hypertensive subjects without DM. ${ }^{7}$ Hyperglycemia also may be an independent risk factor for concentric changes in LV geometry when subjects with mild DM are included. ${ }^{7}$ The pathophysiology of LVH in type $2 \mathrm{DM}$ (T2DM) remains unclear and is not fully explained by the hyperglycemiaassociated cellular alterations. ${ }^{8}$ There is a growing body of evidence that supports the role of inflammation, oxidative stress, AMP-activated kinase, and insulin resistance in mediating the development of $\mathrm{LVH}^{8}{ }^{8}$ Diabetic cardiomyopathy, a diabetes-related myopathic state, is characterized mainly by impaired diastolic function. ${ }^{9}$ Hence, diastolic dysfunction (D/D) is very common among diabetic subject, though systolic dysfunction is not universally present.

Echocardiography is a reliable non-invasive tool to estimation of LVM and has been proven to be a more sensitive tool for the estimation of LV mass and function than other techniques. Very few studies available from India that examine the risk factors related to LVM and LV function in T2DM patients without hypertension. Hence, the aim of this cross-sectional study is to evaluate the $\mathrm{LVH}$ and LV function in normotensive diabetes patients without antihypertensive medication.

\section{Aims and objectives}

The study has the following specific objectives:

1. To compare LVM and LVM index (LVMI) between normotensive diabetic and age- and sex matched normotensive, non-diabetic populations.

2. To determine the LV systolic and diastolic function and compare it with age and sex matched non diabetic patient.
3. To find out the prevalence of high LVM in normotensive type 2 diabetic patients and control patients.

4. To uncover the risk factors for the development of high LVM in normotensive type 2 diabetic patients.

\section{MATERIALS AND METHODS}

This hospital-based observational study with a crosssectional design was conducted at SSKM hospital from May 2018 to April 2019. We included all the normotensive patients attending diabetes outpatient department (OPD) and medicine OPD.

\section{Sampling}

100 normotensive patients, suffering from T2DM, were randomly selected from diabetes OPD of SSKM hospital and 100 age- and sex-matched normotensive controls were selected from medicine OPD.

\section{Inclusion criteria}

The following criteria were included in the study:

a. Diagnosed diabetic patients either on therapeutic lifestyle control or anti-diabetic drugs.

b. Patients who were normotensive and not taking any antihypertensive medication.

c. Age group: 12-65 years.

\section{Exclusion criteria}

The following criteria were excluded from the study:

a. Hypertensive patients or patients on anti-hypertensive medication(s).

b. Known causes of LV hypertrophy such as hypertension, cardiomyopathy, aortic stenosis diabetic nephropathy/ CKD, and athletes heart.

c. Does not give consent for study.

\section{Tools and techniques}

Sphygmomanometer was used to measure blood pressure. Echocardiography was done to measure LVM and systolic and diastolic function of the left ventricle.

\section{Echocardiography}

Echocardiography was done using single machine model VIVID 7 (GE company made). We have used single observer to rule out bias.

Calculation of LVEF was done using Teicholz method. We have used $\mathrm{M}$ mode in parasternal long axis and measured wall thickness during systole and diastole; we have measured LV cavity dimensions during systole and diastole. Subsequently, in built software calculated the EF. We use the American Society of Echocardiography and the European Association of Echocardiography published guideline for the assessment of diastolic function by echocardiography. ${ }^{10}$ 
Measurement of LVM: Devereux and Reichek ${ }^{11}$ cube formula used to assess LV mass. The formula is $\mathrm{LVM}=0.8 \times 1.04\left(\left[\mathrm{LVIDD}+\mathrm{IVS} \mathrm{d}+\mathrm{LVPWd}{ }^{3}-\right.\right.$ LVIDD $\left.^{3}\right)+0.6$. Echocardiographic assessment of LVMI was done using formula LVMI $=\mathrm{LVM} / \mathrm{BSA}$

(LVIDD: Left ventricular internal diameter during diastole, IVSD: Inter-ventricular septal thickness during diastole, LVPWD: Left ventricular posterior wall thickness during diastole, BSA: Body surface area).

\section{Statistical analysis}

Collected data were entered in Statistical Packages for the Social Sciences version 20 and checked for completeness. Descriptive and inferential statistics were used to analyze and present it. Normally distributed data from continuous variables were presented in the form mean $( \pm S D)$ and the data from discrete variables were presented in the form of frequency and proportion. Independent sample t test was performed for normally distributed data from continuous variables and Chi-square test was done for normally distributed data from discrete variables. Correlation was assessed and Pearson correlation coefficient was calculated between LVMI and fasting blood sugar (FBS), post-prandial blood sugar, HbA1C. $\mathrm{P}<0.05$ was considered significant.

\section{Ethical issues}

Ethical clearance was taken from Institutional Ethics Committee (Memo No-Inst/IEC/692) before conducting the study.

Informed consent was taken from all the study participants before recruiting them for the study.

\section{RESULTS}

Mean age of the diabetic patients was 49.27 ( \pm 10.23 ) years while that of non-diabetic population was 47.17 $( \pm 9.44)$ years and the difference was not statistically significant. The proportion of male $(56 \%)$ and female $(44 \%)$ in diabetic patient was not statistically different from that of non-diabetic male (50\%) and female (50\%) (Table 1). This matching was done to rule out any effect of age and sex on LVM. The mean body surface area of diabetic patients was $1.62( \pm 0.10) \mathrm{m}^{2}$ whereas that of non-diabetic patients was noted to be $1.59( \pm 0.08) \mathrm{m}^{2}$ and the difference was not statistically significant. Diabetic patients' mean fasting and post-prandial glucose level and $\mathrm{HbA1C}$ were 144.65 (33.04) mg/dl, 224.87 (54.53), and $7.69(0.59 \%)$, respectively, while the corresponding parameters noted among non-diabetic study participants were $82.44(10.46) \mathrm{mg} / \mathrm{dl}, 115.05$ (15.18) $\mathrm{mg} / \mathrm{dl}$, and $5.73(0.46) \%$ (Table 1$)$.
Echocardiographic measurements of the left ventricular structure and function revealed that - left ventricular internal dimension in diastole (LVIDD), left ventricular posterior wall thickness (LVPWT), and inter ventricular septal thickness (IVST) - were higher in T2DM patients and left ventricular ejection fraction is lower than non-diabetic subjects and the difference was statistically significant. LVM and LVMI were statistically significantly higher in diabetic patient than non-diabetes normotensive patients (Table 2).

LVMI is considered to be increased when it is more than $115 \mathrm{~g} / \mathrm{m}^{2}$ in males and more than $95 \mathrm{~g} / \mathrm{m}^{2}$ in case of females. ${ }^{12,13}$ Increased LVMI was noted among $61 \%$ of the T2DM patients while $5 \%$ of the non-diabetic subjects had increased LVMI and the difference was statistically significant (Table 3).

\begin{tabular}{|c|c|c|c|}
\hline Patients profile & Diabetic (100) & $\begin{array}{l}\text { Non diabetic } \\
(100)\end{array}$ & Pvalue \\
\hline Age in years $( \pm S D)$ & $49.27(10.23)$ & $47.17(9.44)$ & 0.130 \\
\hline \multicolumn{4}{|l|}{ Sex } \\
\hline Male (\%) & $56(56)$ & $50(50)$ & 0.395 \\
\hline Female (\%) & $44(44)$ & $50(50)$ & \\
\hline$B S A$ in $m^{2}( \pm S D)$ & $1.62(0.10)$ & $1.59(0.08)$ & 0.09 \\
\hline FBS in $\mathrm{mg} / \mathrm{dl}$ & $144.65(33.04)$ & $82.44(10.46)$ & 0.001 \\
\hline PPBS in $\mathrm{mg} / \mathrm{dl}$ & $224.87(54.53)$ & $115.05(15.18)$ & 0.001 \\
\hline $\mathrm{HbA} 1 \mathrm{C}$ & $7.69(0.59)$ & $5.73(0.46)$ & 0.001 \\
\hline
\end{tabular}

BSA: Body surface area, FBS: Fasting blood sugar, PPBS: Post-prandial blood sugar

\begin{tabular}{|c|c|c|c|}
\hline $\begin{array}{l}\text { Echo } \\
\text { parameter }\end{array}$ & $\begin{array}{c}\text { Diabetic } \\
\text { Mean ( } \pm \text { SD) }\end{array}$ & $\begin{array}{c}\text { Non-diabetic } \\
\text { Mean ( } \pm \text { SD) }\end{array}$ & $P$ value \\
\hline IVSD & $10.69(1.22)$ & $8.85(0.81)$ & 0.001 \\
\hline LVPWT & $10.49(1.24)$ & $8.82(0.84)$ & 0.001 \\
\hline LVIDD & $46.34(5.10)$ & $43.84(3.91)$ & 0.001 \\
\hline LVIDS & $30.88(4.38)$ & $28.24(3.04)$ & 0.004 \\
\hline LVEF & $61.23(6.53)$ & $65.47(4.20)$ & 0.001 \\
\hline LVM & $186.25(37.76)$ & $128.38(25.37)$ & 0.001 \\
\hline LVMI & $114.38(20.33)$ & $80.60(13.71)$ & 0.001 \\
\hline
\end{tabular}

LVM: Left ventricular mass, LVMI: Left ventricular mass index, LVIDD: Left ventricular internal dimension in diastole, IVSD: Interventricular septal diameter, LVPWT: Left ventricular posterior wall thickness, LVEF: Left ventricular ejection fraction

\begin{tabular}{lccc}
\multicolumn{4}{l}{ Table 3: Prevalence of increased LVMI in T2DM } \\
\multicolumn{4}{l}{ and non-diabetic study subjects } \\
\hline LVMI status & T2DM & Non diabetic & P value \\
& No. (\%) & No. (\%) & \\
\hline Normal & $39(39)$ & $95(95)$ & $<0.001$ \\
Increased & $61(61)$ & $5(5)$ & \\
Total & $100(100)$ & $100(100)$ & \\
\hline
\end{tabular}

LVMI: Left ventricular mass index, T2DM: Type 2 diabetic mellitus 
In this study we found, mean systolic function in diabetes group was 61.23 and that of control group was 65.47 . Although statistically significant different exist between two groups $(\mathrm{P}=0.001)$, in clinical practice there is no difference in systolic function between groups (Figure 1). If we see the $\mathrm{D} / \mathrm{D}$ among control and diabetes group we have found, $49 \%$ of control group patients had no $\mathrm{D} / \mathrm{D}$ and $51 \%$ patients had only Grade-I D/D but in diabetic group, 53\% patients had Grade-I D/D, $37 \%$ patients had Grade-II $\mathrm{D} / \mathrm{D}$, and $6 \%$ patients had Grade-III D/D. Hence, D/D was increasing in patients with diabetic (Table 4).

Correlation of LVMI was assessed with FBS, post-prandial blood sugar (PPBS) and $\mathrm{HbA} 1 \mathrm{C}$ and duration of diabetes. The study revealed positive correlation between LVMI and FBS, PPBS, HbA1C, and duration of diabetes. The Pearson's correlation coefficient was $0.72,0.66,0.76$, and 0.79 , respectively, and the association was statistically significant. The corresponding R2 for FBS, PPBS, and $\mathrm{HbA} 1 \mathrm{C}$ and the duration of diabetes were $0.52,0.44,0.58$, and 0.62 or in other words the study has revealed that $52 \%$, $44 \%$, and $58 \%$ variability in LVMI can be explained by FBS, PPBS, and $\mathrm{HbA} 1 \mathrm{C}$, respectively (Table 5 and Figures 2-4).

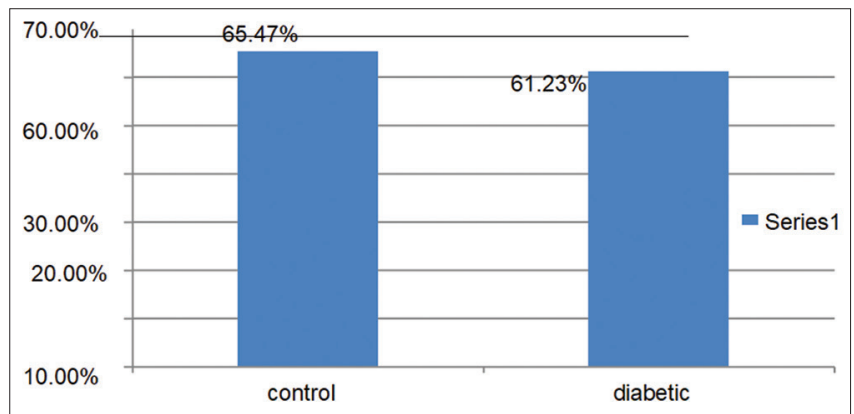

Figure 1: Bar diagram showing the left ventricular systolic function in control and diabetic patients

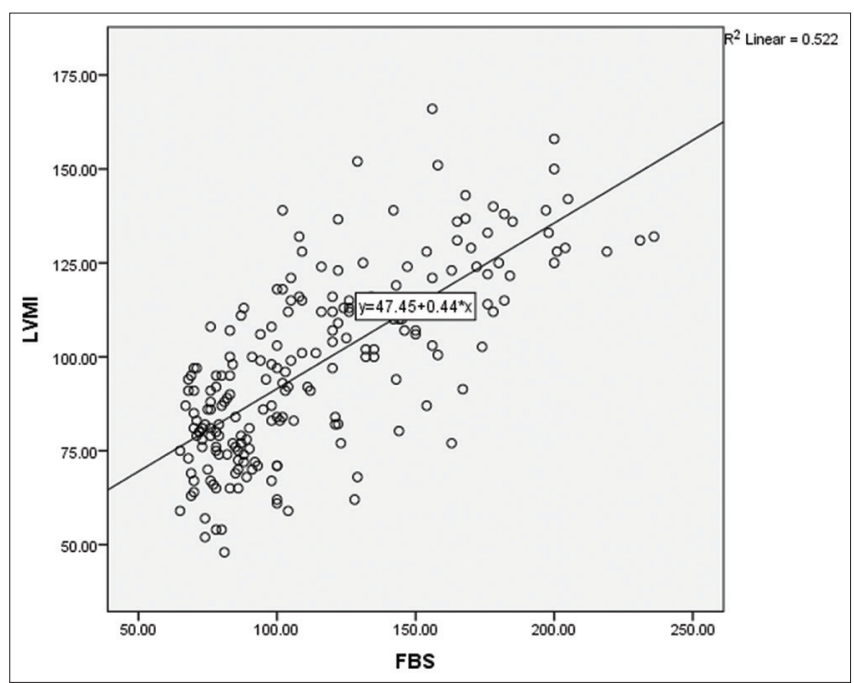

Figure 2: Correlation of LVMI with FBS. LVMI: Left ventricular mass index, FBS: Fasting blood sugar

\section{DISCUSSION}

Majority of patients with DM eventually suffer from cardiac ailment and DM remains crucial factor in overall diabetic morbidity and mortality. Increased LVM may contribute to the increased cardiovascular risk because $\mathrm{LVH}$ is an important prognostic sign and an independent risk factor for sudden death, ventricular dysrhythmia, myocardial ischemia, coronary heart disease, and heart failure.

Our cross-sectional study demonstrated that increased LVMI is to be a common association in normotensive type 2 diabetic patients predominantly without micro- or macr-ovascular complications and hypertension compared to the age- and sex-matched, normotensive, and nondiabetic control population. In our study group, none of the patients were receiving antihypertensive medication. In this study, LVM and LVMI were compared with the BSA to avoid the influence of obesity. We also observed that the mean of LVM and LVMI was statistically significantly high (in both case $\mathrm{P}<0.001$ ) in diabetic patients in comparison to healthy control subjects. This indicates the association of high LVM in patients of DM. A study from Japan demonstrated that LVM and LVMI were significantly greater in the normotensive T2DM patients than the normotensive control population, by

\begin{tabular}{|c|c|c|c|}
\hline \multirow{2}{*}{$\begin{array}{l}\text { Diastolic } \\
\text { dysfunction } \\
\text { grading }\end{array}$} & \multicolumn{2}{|c|}{ Groups } & \multirow[t]{2}{*}{ Total } \\
\hline & Control & Diabetic & \\
\hline \multicolumn{4}{|l|}{$\mathrm{D} / \mathrm{D}$} \\
\hline \multicolumn{4}{|l|}{0} \\
\hline Count & $50(92.6 \%)$ & $4(07.4 \%)$ & $54(100 \%)$ \\
\hline$\%$ within Groups & 50 & 4 & 24.8 \\
\hline \multicolumn{4}{|l|}{ 1 } \\
\hline Count & $50(48.5 \%)$ & $53(51.5 \%)$ & $103(100 \%)$ \\
\hline$\%$ within Groups & 50.0 & 53.0 & 52.0 \\
\hline \multicolumn{4}{|l|}{ ॥ } \\
\hline Count & 0 & $37(100 \%)$ & $37(100 \%)$ \\
\hline$\%$ within Groups & 0.0 & 37.0 & 18.3 \\
\hline \multicolumn{4}{|l|}{ III } \\
\hline Count & 0 & $6(100 \%)$ & $6(100 \%)$ \\
\hline$\%$ within Groups & 0.0 & 6.0 & 3.0 \\
\hline
\end{tabular}

\begin{tabular}{lccc}
$\begin{array}{l}\text { Table 5: Correlation of LVMI with glycemic } \\
\text { status of the study variables }\end{array}$ & \\
\hline Glycemic status & $\begin{array}{c}\text { Pearson's correlation } \\
\text { co-efficient }\end{array}$ & $\mathbf{R}^{2}$ & P value \\
\hline FBS & 0.72 & 0.52 & $<0.001$ \\
PPBS & 0.66 & 0.44 & $<0.001$ \\
HbA1C & 0.76 & 0.58 & $<0.001$ \\
$\begin{array}{l}\text { Duration of } \\
\text { diabetes }\end{array}$ & 0.79 & 0.62 & $<0.001$ \\
\hline
\end{tabular}

LVMI: Left ventricular mass index, FBS: Fasting blood sugar, PPBS: Post-prandial blood sugar 


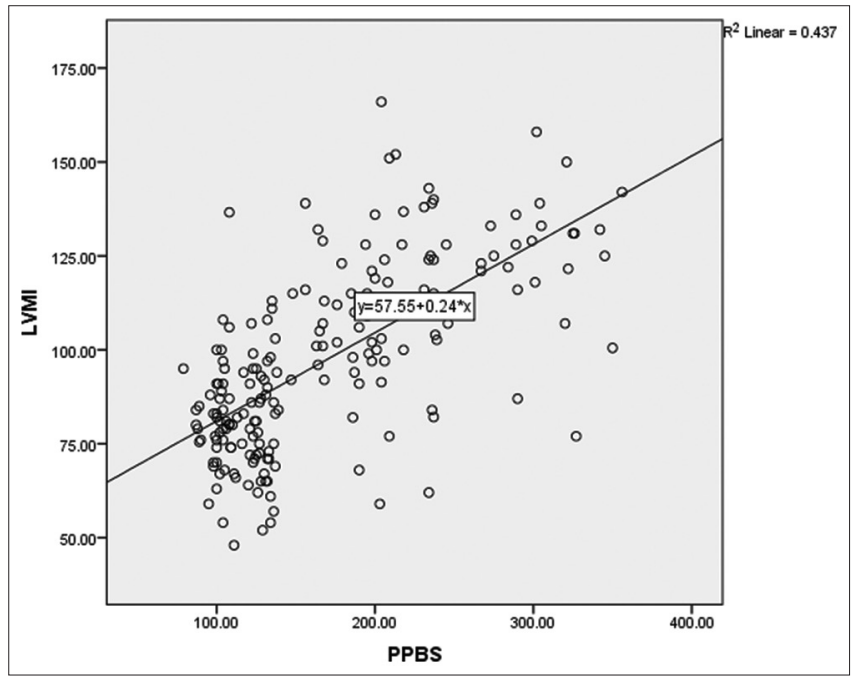

Figure 3: Correlation of LVMI with PPBS. LVMI: Left ventricular mass index, PPBS: Post-prandial blood sugar

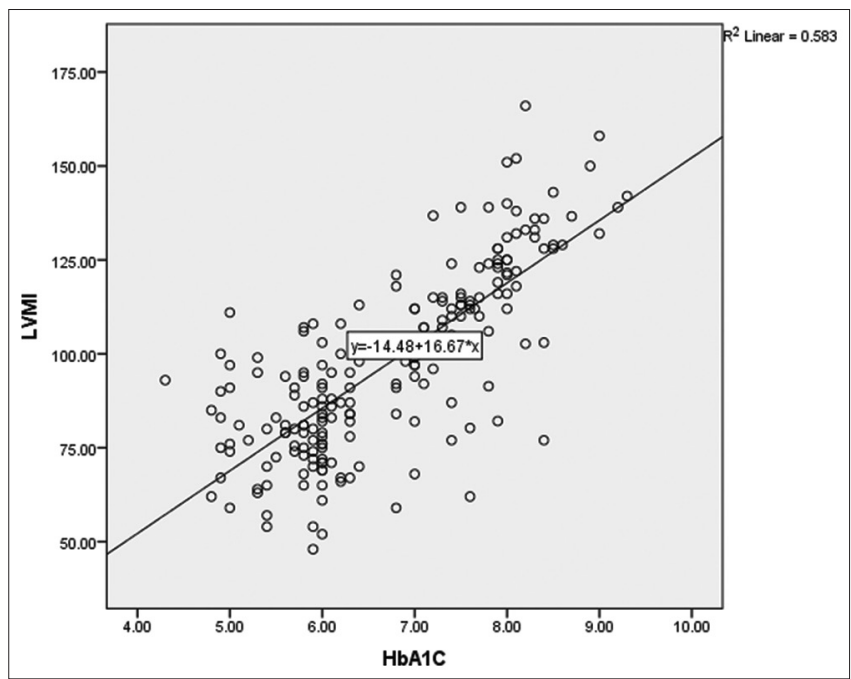

Figure 4: Correlation of LVMI with HbA1C. LVMI: Left ventricular mass index

Hirayama et al., ${ }^{3}$ Hence our results corroborated with that study.

In our study, it was also observed that the mean values of LVPWT, IVST, and LVIDD (in all cases P<0.001) were statistically significantly high in diabetic patients in comparison to healthy control subject. The increased ventricular wall thickness and left ventricular dilatation, both contribute to the observed increase in LVM. This study shows that cardiac muscle disease complicates diabetes in subjects who do not have hypertension. In this study, we also found that there is a significant difference in LVM between normotensive, T2 DM patients and the control group. Diabetic patients had higher relative wall thickness ( 0.50 vs. $0.44, \mathrm{P}<0.001)$ and higher prevalence of concentric LV hypertrophy (39.4\% vs. $26.8 \%, \mathrm{P}<0.001$ ) than non-diabetic patients. ${ }^{14}$ This finding is important as increased LVM is contributor to increased cardiovascular morbidity and mortality. Hence, early diagnosis and prevention is important to prevent patients from sufferings; drug therapy can lead to improvement in the left ventricular function and can decrease cardiovascular morbidity. The high prevalence of LVH in diabetic patients supports this idea that early echocardiographic screening is prudent and may be beneficial to these patients.

The prevalence of LVH in the predominantly non-diabetic population (CI 95\%) calculated in the Framingham Heart Study assessed by echocardiography was reported to be $16 \%$ in men and $21 \%$ in women. In our study, the prevalence of increased LVMI (normal upper limit for LVMI in female $<95 \mathrm{~g} / \mathrm{m}^{2}$ and in male $\left.<115 \mathrm{~g} / \mathrm{m}^{2}\right)^{12,13}$ was $4.9 \%$ (2\% in male and $7.8 \%$ in female) in control population but $60 \%$ (46\% in male and $79.5 \%$ in female) is significantly higher. The prevalence of $\mathrm{LVH}$ increases with the severity of hypertension, ranging from $38 \%$ to $72 \%$ in hypertensive diabetic populations. ${ }^{14}$ In the present study, nearly $60 \%$ of patients had LVH, even though none of the included type 2 diabetic patients was receiving or had prior treatment with antihypertensive medications, and all had an arterial blood pressure below the recommended cutoff of $140 / 90 \mathrm{mmHg}$. While other studies have found a relationship between arterial blood pressure and LVM in diabetic patients with and without hypertension, this was not the case in the present study, where blood pressure levels were lower. Interestingly, in non-diabetic population, LVH is commonly associated with ischemic heart diseases and vice versa; however, evidence suggests that ischemic heart disease is a consequence rather than cause of LVH. A cohort of more than 5000 patients and found that the increased wall thickness of the ventricular septum or of the left ventricular posterior wall was not associated with prevalent coronary heart disease by Lee et al., ${ }^{4}$ Consequently, our findings of an increased wall thickness could not be explained by such a mechanism. Although this study was conducted with normotensive patients, it appeared clearly that features of diabetic cardiomyopathy were associated with increasing blood pressure levels. Increasing blood pressure could either be an etiologic factor or simply part of the hemodynamic features of diabetic cardiomyopathy as reported in experimental studies.

An increased heart size may reflect the increase in the circulating blood volume and systolic dysfunction could be secondary to increased peripheral resistance, as some studies have shown increasing peripheral resistance in diabetic patients. We have found a statistically significant difference of systolic function in diabetic patients in comparison to non-diabetic non hypertensive patients. This could therefore be attributable to early changes 
preceding established hypertension. Our study also showed that $\mathrm{D} / \mathrm{D}$ was increasing in patients with diabetic without hypertension than the control group. This $\mathrm{D} / \mathrm{D}$ is explained by the increase LVM as found in diabetic group of patients. In humans, left ventricular D/D (LVDD) is considered the earliest manifestation of diabetic cardiomyopathy, preceding the development of systolic dysfunction. ${ }^{16}$ Patients with T2DM had an additional worsening in diastolic function parameters, such as E' velocity and E/E' ratio, and a further increased prevalence of $\mathrm{LVDD}^{17} \mathrm{~A}$ positive correlation between severity of $\mathrm{CAD}$ assessed using $\mathrm{SS}$ and $\mathrm{E} / \mathrm{A}$ and $\mathrm{E} / \mathrm{e}$ ' and LAVI which are various determinants of DD, was found from a study conducted by Mukhopadhyay et al. ${ }^{18}$ Diastolic function seems more susceptible to ischemia than systolic function and can take longer to recover. ${ }^{19,20}$ So this increase association of $\mathrm{D} / \mathrm{D}$ in patients with diabetes as shown in our study, is also an important predictor of adverse cardiovascular outcome, early detection and treatment may improve morbidity and mortality in the diabetic patients.

In our study, type 2 diabetes patients with common risk factors for the development of $\mathrm{LVH}$, such as hypertension, albuminuria, thyroid disorder, ischemic heart diseases, and dyslipidemia were excluded from the study. We have found that the LVMI increased with the longer duration of diabetes and poor glycemic control as suggested by higher HbAIc in the diabetic population with LVH. Sato et al., also reported a significant correlation between glycemic control, duration of DM, and severity of nephropathy and LVMI. ${ }^{21}$ That urinary albumin excretion rate is strongly associated with the degree of LVM hypertrophy has been demonstrated in several previous studies of non-diabetics and type 1 and type 2 diabetic patients with micro and macroalbuminuria. ${ }^{22}$ Furthermore, in hypertensive diabetic and non-diabetic patients with LVH, an increased urinary albumin excretion rate resulted in an increased risk for cardiovascular morbidity and mortality. ${ }^{23}$ However, in our study, we had selected the patients from both diabetic and healthy control groups, those having no micro- and macroalbuminuria. Hence, in this study, albuminuria was not the cause of LVH. In addition to blood pressure, urinary albumin excretion rate, BMI, and blood glucose ${ }^{24}$ it has also been suggested that coronary microvascular dysfunction, endothelial dysfunction and chronic inflammation, and abnormalities in the tissue renin-angiotensin-aldosterone-bradykinin system or the encoding genes might play a role in the pathogenesis of $\mathrm{LVH}^{25}$ The observation that some type 2 diabetic patients have asymmetrical and some have concentric hypertrophy might suggest that the underlying pathology is not homogenous, but rather reflects the interaction of several of the above-mentioned risk factors.

\section{Limitations of the study}

Few limitations of our study are: (1) No molecular analysis was done why LVH occurs in diabetes. (2) We must say that this type of study demands much more time and more number of patients. (3) No long term follow-up was done. (4) No coronary angiogram was done. Ischemic heart disease was ruled out only by ECG and echocardiogram. However, further studies with a larger cohort of patients are needed.

\section{CONCLUSION}

Our case-control study showed that LVM is significantly higher in type 2 diabetic patients without hypertension as compared to healthy compatible control group. The diastolic and systolic dysfunction also increases in patients with diabetes without hypertension. Hence, LVM screening is a mandatory workup in all T2DM patients for the prognostication of morbidity and mortality. LVM is increased with the duration of diabetes. LVM is also increased with the HbAIc level and a poor glycemic control. Hence, patients with a longer duration of diabetes with poor glycemic control have more chances of having LVH. Hence, a large, prospective, double-blind study design will further reveal the actual prevalence of LVM in such population. Our study in that sense is a sort of eye opener work.

\section{REFERENCES}

1. Levy D, Garrison R, Savage D, Kannel W and Castelli W. Prognostic implications of echocardiographically determined left ventricular mass in the Framingham heart study. $\mathrm{N}$ Engl $\mathrm{J}$ Med. 1990;322(22):1561-1566.

https://doi.org/10.1056/NEJM199005313222203

2. Whiting DR, Guariguata L, Weil C and Shaw J. IDF diabetes atlas: Global estimates of the prevalence of diabetes for 2011 and 2030, Diabetes Res Clin Pract. 2011;94(3):311-321.

https://doi.org/10.1016/j.diabres.2011.10.029

3. Hirayama H, Sugano M, Abe N, Yonemochi H and Makino N. Determination of left ventricular mass by echocardiography in normotensive diabetic patients. Jpn Circ J. 2000;64(12):921-924. https://doi.org/10.1253/jcj.64.921

4. Lee M, Gardin JM, Iynch JC, Smith UE, Tracy RP, Savage PJ, et al. Diabetes mellitus and echocardiographic left ventricular function in free-living elderly men and women: The cardiovascular health study. Am Heart J. 1997;133(1):36-43.

https://doi.org/10.1016/S0002-8703(97)70245-X

5. Ichkhan K, Molnar $\mathrm{J}$ and Somberg J. Relation of left ventricular mass and QT dispersion in patients with systematic hypertension. Am J Cardiol. 1997;79(4):508-511.

https://doi.org/10.1016/S0002-9149(96)00797-7

6. Santra S, Basu AK, Roychowdhury P, Banerjee R, Singhania P, Singh $S$, et al. Comparison of left ventricular mass in normotensive Type 2 diabetes mellitus patients with that in the nondiabetic population. J Cardiovasc Dis Res. 2011;2(1):50-56. https://doi.org/10.4103/0975-3583.78597 
7. Ohya Y, Abe I, Fujii K, Ohmori S and Onaka U, Kobayashi K and Fujishima M. Hyperinsulinemia and left ventricular geometry in a work-site population in japan. Hypertension. 1996;27(3):729-734. https://doi.org/10.1161/01.hyp.27.3.729

8. Mohan M, Dihoum A, Mordi IR, Choy AM, Rena G and Lang CC. Left ventricular hypertrophy in diabetic cardiomyopathy: A target for intervention. Front Cardiovasc Med. 2021;8:746382. https://doi.org/10.3389/fcvm.2021.746382

9. Ren J, Sowers JR, Walsh MF and Brown RA. Reduced contractile response to insulin and IGF-1 in ventricular myocytes from genetically obese Zucker rats. Am J Physiol. 2000;279(4):H1708-H1714 https://doi.org/10.1152/ajpheart.2000.279.4.H1708

10. Kirkpatrick JN, Vannan MA, Narula $J$ and Lang RM. Echocardiography in heart failure: Applications, utility, and new horizons. J Am Coll Cardiol. 2007;50(5):381-396.

https://doi.org/10.1016/j.jacc.2007.03.048

11. Devereux RB and Reichek N. Echocardiographic determination of left ventricular mass in man. Anatomic validation of the method. Circulation. 1977;55(4):613-618.

https://doi.org/10.1161/01.CIR.55.4.613

12. Mor-Avi V, Sugeng L, WeinertL, MacEneaney P, Caiani EG, Koch R, et al. Fast measurement of left ventricular mass with real-time three-dimensional echocardiography: Comparison with magnetic resonance imaging. Circulation. 2004;110(13):1814-1818. https://doi.org/10.1161/01.CIR.0000142670.65971.5F

13. Lang RM, Bierig M, Devereux RB, Flachskampf FA, Foster E, Pellikka PA, et al. Recommendations for chamber quantification: Areport from the American society of echocardiography's guidelines and standards committee and the chamber quantification writing group, developed in conjunction with the European association of echocardiography, a branch of the European society of cardiology. J Am Soc Echocardiogr. 2005;18(12):1440-1463.

https://doi.org/10.1016/j.echo.2005.10.005

14. Hirayama $\mathrm{H}$, Sugano $\mathrm{M}$, Abe $\mathrm{N}$, Yonemochi $\mathrm{H}$ and Makino $\mathrm{N}$. Determination of left ventricular mass by echocardiography in normotensive diabeticpatients. Jpn Circ J. 2000;64(12):921-924. https://doi.org/10.1253/jcj.64.921

15. Eguchi K, Kario K, Hoshide S, Ishikawa J, Morinari M and Shimada K. Type 2 diabetes is associated with left ventricular concentric remodeling in hypertensive patients. Am J Hypertens. 2005;18(1):23-29.

https://doi.org/10.1016/j.amjhyper.2004.08.024

16. Palmieri V, Bella JN, Arnett DK, Liu JE, Oberman A, Schuck MY, et al. Effect of Type 2 diabetes mellitus on left ventricular geometry and systolic function in hypertensive subjects: Hypertension genetic epidemiology network (HyperGEN) study.
Circulation. 2001;103(1):102-107.

https://doi.org/10.1161/01.CIR.103.1.102

17. Boudina $S$ and Abel ED. Diabetic cardiomyopathy revisited. Circulation. 2007;115(25):3213-3223. https://doi.org/10.1161/CIRCULATIONAHA.106.679597

18. Fontes-Carvalho R, Ladeiras-Lopes R, Bettencourt P, LeiteMoreira A and Azevedo A. Diastolic dysfunction in the diabetic continuum: Association with insulin resistance, metabolic syndrome and Type 2 diabetes. Cardiovasc Diabetol. 2015;14:4. https://doi.org/10.1186/s12933-014-0168-x

19. Mukhopadhyay T, Gupta A, Biswas U and Majumdar B. Severity of coronary artery disease and echocardiographic parameters of ventricular diastolic function in patients with non-ST-elevation acute coronary syndrome. Int $\mathrm{J}$ Med Sci Public Health. 2019;8(1):86-90.

https://doi.org/10.5455/ijmsph.2019.1029027102018

20. Carluccio E, Biagioli P, Alunni G, Murrone A, Leonelli V, Pantano $P$, et al. Effect of revascularizing viable myocardium on left ventricular diastolic function in patients with Ischaemic cardiomyopathy. Eur Heart J. 2009;30(12):1501-1509. https://doi.org/10.1093/eurheartj/ehp125

21. Chaowalit $N$, Auesethasak R, Santanakorn $Y$, Jakrapanichakul $D$, Kittipovanonth M, Chirakarnjanakorn S, et al. Patients with nonsT-segment elevation myocardial infarction present with more severe systolic and diastolic dysfunction than patients with unstable angina. J Med Assoc Thai. 2011;94 Suppl 1:S19-S24.

22. Sato $A$, Tarnow $L$ and Parving $H H$. Prevalence of left ventricular hypertrophy in Type 1 diabetic patients with diabetic nephropathy. Diabetologia. 1999;42(1):76-80.

https://doi.org/10.1007/s001250051116

23. Fesler $P$, du Cailar $G$, Ribstein $J$ and Mimran A. Left ventricular remodeling and renal function in never-treated essential hypertension. J Am Soc Nephrol. 2003;14(4):881-887. https://doi.org/10.1097/01.ASN.0000057855.93268.9F

24. Nielsen FS, Ali S, Rossing P, Bang LE, Svendsen TL, Gall MA, et al. Left ventricular hypertrophy in non-insulin-dependent diabetic patients with and without diabetic nephropathy. Diabetic Med. 1997;14(7):538-546.

https://doi.org/10.1002/(sici)1096-9136(199707)14:7<538:aiddia415>3.0.co; $2-i$

25. LeWachtell K, Ibsen H, Olsen MH, Borch-Johnsen K, Lindholm LH, Mogensen $\mathrm{CE}$, et al. Albuminuria and cardiovascular risk in hypertensive patients with left ventricular hypertrophy: The LIFE study. Ann Intern Med. 2003;139(11):901-906. https://doi.org/10.7326/0003-4819-139-11-200312020-00008

\footnotetext{
Authors' Contributions:

TM- Concept and design of the study, reviewed the literature and manuscript preparation; PS- Concept and design of the study, Interpreted the results; prepared first draft of manuscript, reviewed the literature, and manuscript preparation; UB- Coordination, statistical analysis and interpretation, preparation of manuscript, and revision of the manuscript; SN- statistical analysis and interpretation and revision of the manuscript; SISK- Concept and design of the study, interpretation, and revision of the manuscript.

Work attributed to:

This hospital-based cross-sectional, observational study was conducted at IPGME\&R and SSKM Hospital, Kolkata - 700 020, West Bengal, India.

ORCID ID:

Dr. Tanmay Mukhopadhyay - (D) https://orcid.org/0000-0003-1134-7774

Pankaj Sarkar - https://orcid.org/0000-0003-3547-6618

Somnath Naskar - id https://orcid.org/0000-0002-0233-1378

Dr. Uttam Biswas - (1) https://orcid.org/0000-0002-4497-4478

Saidul Islam SK - (1) https://orcid.org/0000-0001-6331-6799

Source of Funding: None, Conflicts of Interest: None.
} 